Yale National Clinician Scholars Program, Yale School of Medicine, New Haven, CT, USA

2 Veterans Affairs Connecticut Healthcare System and Yale University, West Haven, CT, USA

3 Yale School of Medicine, New Haven, CT, USA

4 Department of Internal Medicine, Yale School of Medicine, New Haven, CT USA

5 Department of Health Policy and Management, Yale School of Public Health, New Haven, CT, USA

6 Center for Outcomes Research and Evaluation, Yale-New Haven Hospital, New Haven, CT, USA

Correspondence to: R Ramachandran reshma.ramachandran@yale.edu Cite this as: BMJ2021;373:n1467 http://dx.doi.org/10.1136/bmj.n1467 Published: 22 June 2021

\section{Future of covid-19 vaccine pricing: lessons from influenza}

\section{Routine use of covid-19 vaccines could strain health budgets if pricing follows the pattern seen with influenza vaccines, say Reshma Ramachandran and colleagues}

\author{
Reshma Ramachandran, ${ }^{1,2}$ Meera Dhodapkar, ${ }^{3}$ Joseph S Ross, ${ }^{4,5,6}$ Jason L Schwartz ${ }^{5}$
}

The increasing availability of covid-19 vaccines has signalled to many the beginning of the end of a devastating pandemic. Yet evidence is emerging that the novel coronavirus will continue to evolve and that immunity from vaccines is likely to be time limited, requiring use of booster doses or modified vaccines. Bilateral bulk purchasing agreements between individual countries and manufacturers have allowed vaccines to be procured at lower prices and dispensed to patients without charges. After the pandemic, however, the future pricing landscape of covid-19 vaccines remains unclear.

Multiple parallels exist between covid-19 and influenza vaccines with respect to their development history, market, and administration. Their common features may inform manufacturer behaviour and guide policy measures in the US and other high income countries. If the pattern observed with influenza vaccines is repeated, higher prices for covid-19 vaccines set by companies in the future would have important implications for health spending, public health programme budgets, and insurance premiums.

\section{Pricing landscape for covid-19 vaccines}

Substantial public investment has facilitated the rapid development of covid-19 vaccines. Nearly all the development of the Oxford-AstraZeneca vaccine was funded by governments or charities, ${ }^{1}$ and the German government contributed \$445m (£345m; $€_{375 \mathrm{~m})}$ to the development of Pfizer-BioNTech's vaccine. ${ }^{2}$ The US government initiative Operation Warp Speed alone has contributed an estimated \$18bn towards the development and manufacturing of covid-19 vaccines. ${ }^{3}$ Legislators and advocates have expressed concern over whether the eventual prices of these vaccines will reflect a fair return on public investment. At a 2020 hearing of a US House oversight and investigations subcommittee, leading manufacturers were asked if they would supply covid-19 vaccines at cost or no profit. Only two, AstraZeneca and Johnson \& Johnson, stated they would, for a limited number of doses or during "the emergency pandemic period.” Pfizer and Moderna both said that they would not. ${ }^{4}$

Immunologists ${ }^{5}$ and manufacturers ${ }^{6} 7$ have announced that covid-19 vaccination may need to occur at least annually to sustain sufficient immune response and protect against rapidly emerging variant strains. Uncertainty is further fuelled by the lack of clarity around how to define the "pandemic period"-when companies have promised to supply their products at lower prices or share technology 8 with other manufacturers. For instance, internal documents revealed that although AstraZeneca pledged not to profit from its vaccine during the pandemic period, it also specified that it could declare the pandemic to have concluded by July $2021 .{ }^{9}$ Pharmaceutical executives have also stated they anticipate returning to "commercial pricing” as early as later this year, with one head at Pfizer noting that a normal price outside the pandemic would be “ $\$ 150$, \$175 per dose." ${ }^{10}$ Already, Pfizer has raised the prices of the European Union's future orders of its vaccine by over $60 \% .^{11}$

Even before authorisation and approval, countries entered into bilateral bulk purchasing agreements with individual manufacturers to secure doses at lower negotiated prices. ${ }^{12}$ Through two separate agreements Moderna secured a \$3.2bn contract to provide the US with 200 million doses. ${ }^{13}$ This is roughly \$16 a dose, compared with the \$37-\$39 it initially announced. The EU secured doses from Moderna at $\$ 18$ each. Pfizer also received two separate contracts for a total of 200 million doses at $\$ 19.50$ a dose, ${ }^{14}$ while the EU paid just under $\$ 15 .{ }^{15}$

It remains unclear how covid-19 vaccines will be priced in future as more candidates enter the market. Constraints on manufacturing capacity-and therefore supply-as well as the need for mass global vaccination campaigns may allow for a market with multiple, similarly efficacious vaccines. The development pipeline for covid-19 vaccines remains active: as of May 2021, 99 vaccine candidates were in clinical development worldwide with 19 in phase III trials. ${ }^{16}$

\section{Parallels to the influenza vaccine}

Although the development and ongoing distribution of covid-19 vaccines is without precedent, the closest analogue is the influenza vaccine in the United States. Similar to covid-19 vaccines, multiple flu vaccines are produced by various manufacturers, largely used interchangeably. Moreover, scientists anticipate that SARS-CoV-2 will be endemic, ${ }^{17}$ like the influenza virus. Influenza vaccines are administered in various clinical and non-clinical settings, with tens of millions of doses rapidly administered annually over a few months each year, as is currently occurring and will likely continue for covid-19.

Additionally, just as the covid-19 vaccine is being tested and updated in response to rapidly emerging virus variants, the influenza vaccine is reviewed and modified annually to prevent against mutated strains. ${ }^{1819}$ No "game changing" antiviral treatment currently exists for influenza or covid-19, making vaccination the centrepiece of public health measures for prevention both of future epidemics and of morbidity and mortality from the infection. 
Like the covid-19 vaccine, public funding in the context of a deadly pandemic spurred the discovery and development of the influenza vaccine, in the latter case through the Department of Defense. ${ }^{20}$ Even today, federal laboratories have an important role in developing and manufacturing seasonal influenza vaccine. ${ }^{21} 22$

\section{Pricing trends for influenza vaccines}

Over the past two decades, the number of doses of influenza vaccine distributed throughout the US has generally risen steadily each year (see supplementary figure on bmj.com). Significant exceptions to this are the 2004-05 flu season (when the production plant of one of the two manufacturers supplying doses to the US failed FDA inspections ${ }^{23}$ ) and the 2011-12 flu season (after a large rise in doses the previous year when the US immunisation advisory committee recommended that everyone aged 6 months and older should receive the vaccine and the $2009 \mathrm{H} 1 \mathrm{~N} 1$ pandemic ${ }^{24}$ contributed to increased procurement $^{25}$ ).

As with covid-19, the Centers for Disease Control and Prevention (CDC) and other federal agencies can procure influenza vaccines at lower prices than the private sector through bulk purchasing agreements. It is unclear how many doses the CDC has purchased each year and whether the amount purchased could affect the negotiated price. However, it was reported that for the 2020-21 flu season, in what was described as an "unprecedented move," the CDC purchased seven million doses directly from manufacturers for $\$ 100 m$ or $\$ 14$ each $^{26}$-a higher price than it has previously negotiated.

As the number of influenza vaccine doses supplied in the US has increased over time, it might be expected that prices would also decrease, in accordance with traditional economic principles. However, the opposite was observed from the annual CDC contract (or public sector) and private sector prices. From 2000 to 2021, average prices for the influenza vaccine rose by $149 \%$ for the public sector and $163 \%$ for the private sector (fig 1 ). Average private sector prices, which were consistently higher than public sector prices, largely plateaued between the 2015-16 and 2020-21 flu seasons, rising only by $7 \%$ during this time. Notably, prices between the private and public sectors further diverge after the 2009-10 flu season. Lower public sector prices may be due to increased government procurement following the $\mathrm{H}_{1} \mathrm{~N} 1$ pandemic in late 2009 and the advisory committee's decision in 2010 to broaden the recommended population for receiving the vaccine.

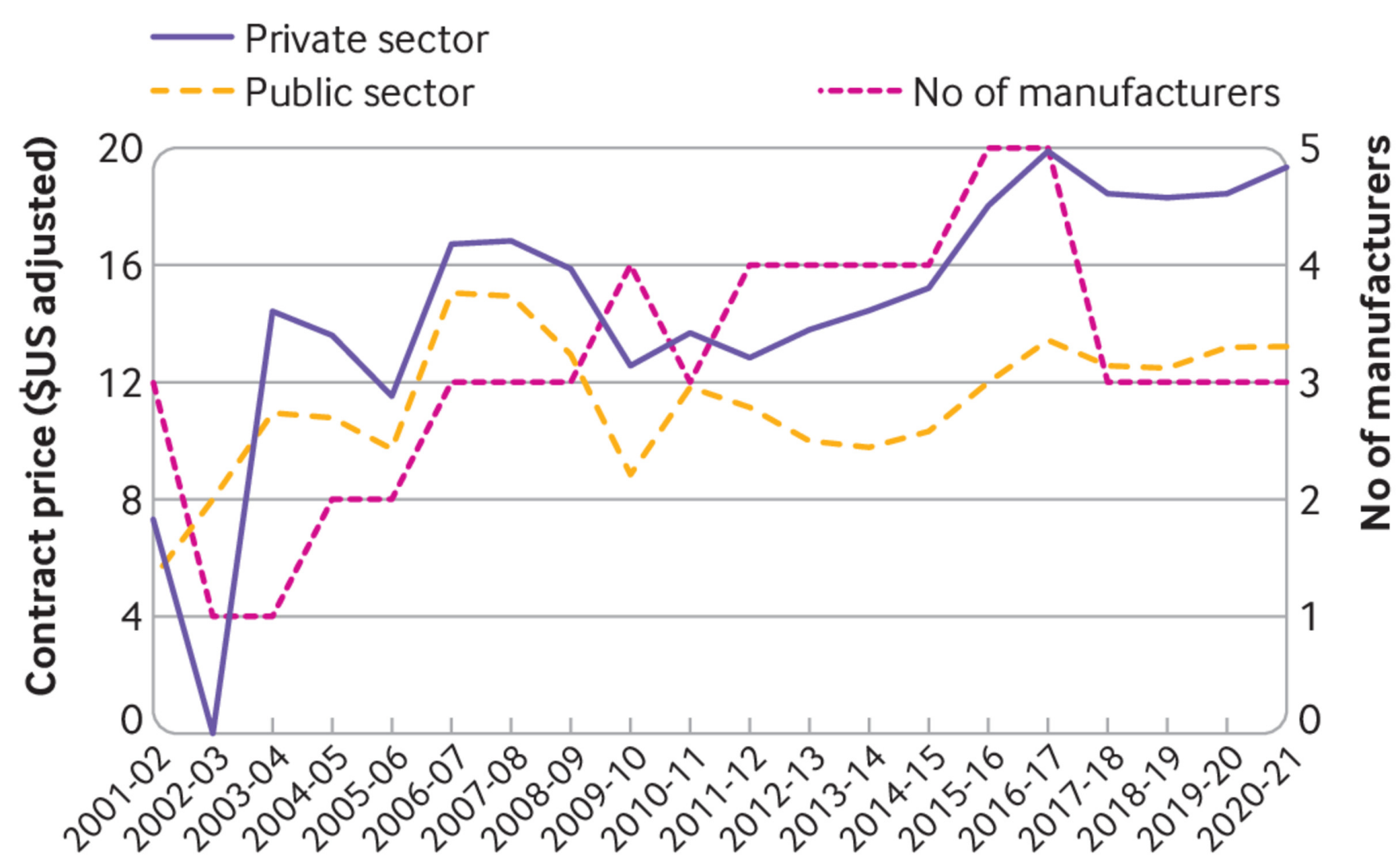

\section{Annual flu season}

Fig 1 | Average public and private sector prices for influenza vaccines in the United States (2000-21). Prices adjusted to 2020 US dollars, with average prices calculated from reported contract prices in either August or September (or if unavailable, a month that would be representative for that year's full season). ${ }^{27}$ Numbers above set of bars denote number of products for that flu season. FluMist was excluded as it would not be considered an equivalent product to the other vaccine products on the market and its price was significantly higher

Pricing trends for the influenza vaccine also do not seem to be affected by the number of manufacturers and products on the market (fig 1). The three manufacturers in the US with the biggest market share $^{28}$ (Sanofi-Pasteur, CSL, and GlaxoSmithKline) have seen mean compound annual growth rate over the 10 years from 2011 to 2021 of $2.2 \%$ (range $1.1 \%-3.8 \%$ ) for average public sector prices and $4.1 \%$ (range $2.6 \%-6.8 \%$ ) for public sector prices (fig 2). The annual 
growth rate of the consumer price index for prescription drugs over $\quad$ the same period was just $1.8 \%$.
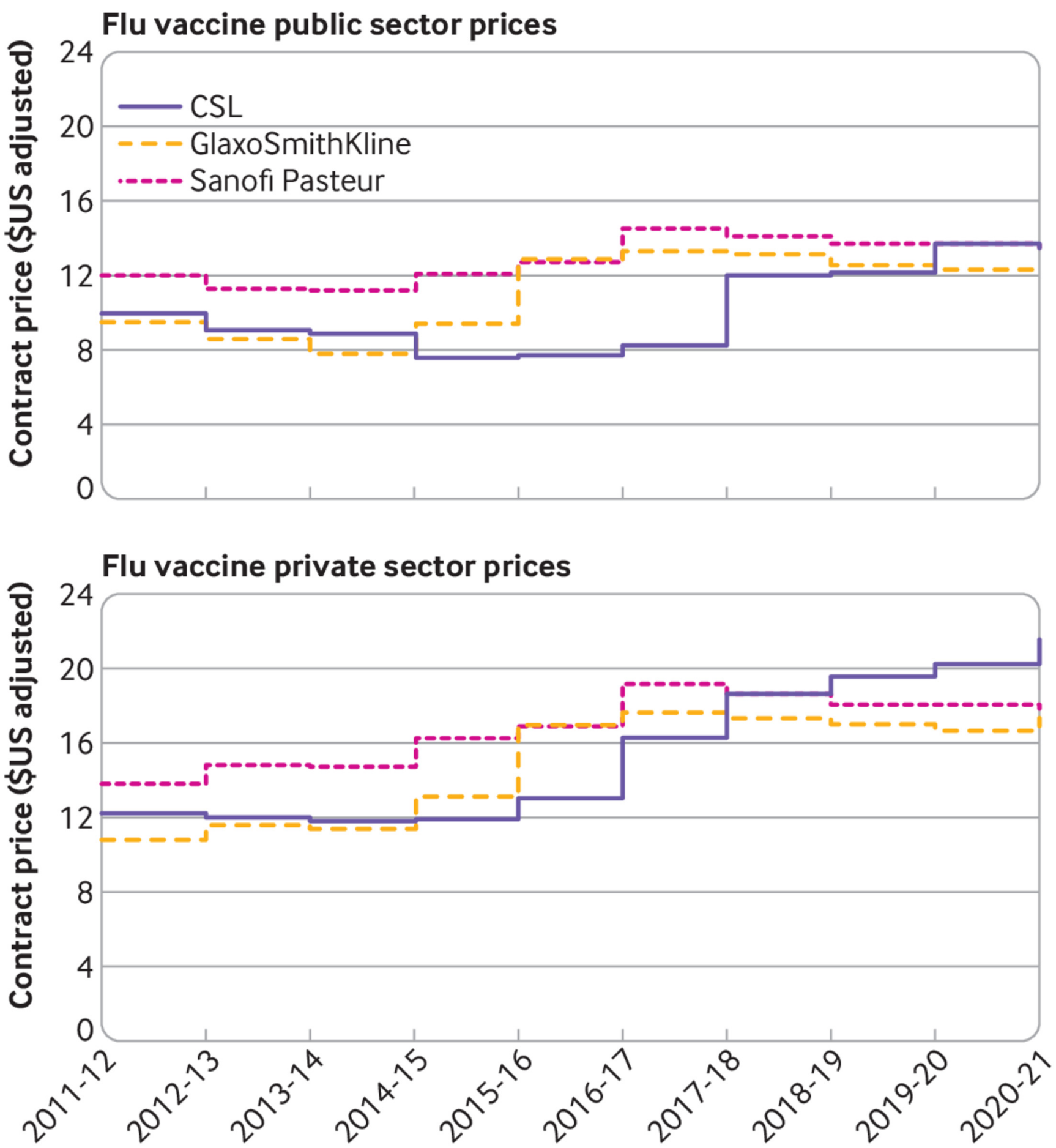

Annual flu season

Fig 2 | Trends in US influenza vaccine prices for three manufacturers (2011-21) in public and private sector. (Prices adjusted to 2020 \$)

To assess whether these manufacturers behaved similarly-that is, if one manufacturer raised their prices, did another manufacturer as well- we measured correlations of their average public and private sector prices over time using the Kendall $\tau-b(\tau b)$ coefficient. We found relatively high correlations between GlaxoSmithKline and Sanofi Pasteur across both sectors (public $=0.778$; private $=0.822$ ), suggesting little price competition between them during this period. CSL prices were poorly correlated with those of the other two companies (public $=0.067$ (GSK), 0.200 (Sanofi); private=0.466 (GSK), 0.377 (Sanofi)). Following the 2016-17 flu season the average price of CSL's products rose substantially across both sectors while average prices for GlaxoSmithKline and Sanofi Pasteur slightly 
decreased or plateaued. This suggests that the influenza vaccine market in the US has little price competition but steadily rising prices, despite growing government purchasing commitments and broadening populations of recommended users. However, public reporting of supply data for individual products procured by the public and private sector would be necessary to further inform price competition analyses.

\section{Achieving fair pricing}

Pricing trends for influenza vaccines in the US since the 2000-01 flu season portend a potentially perilous future for ensuring fair pricing of covid-19 vaccines. Despite having multiple manufacturers selling similar products to an expanding market over time, like the influenza vaccine, the prices of covid-19 vaccines are expected to rise in the coming years. After the immediate pandemic period, the private sector is likely to procure booster doses at higher prices than the public sector. If the pattern observed with influenza vaccines is repeated, future higher prices for covid-19 vaccines would have substantial implications for health spending, public health programme budgets, and insurance premiums for those with private insurance.

Some countries have already committed to publicly procuring additional doses for booster vaccinations potentially needed later this year, ${ }^{29} 30$ which may help mitigate price increases. However, companies may still raise prices, as has been seen previously in high income countries during government procurement of influenza vaccines. ${ }^{31}$ Another possibility is that countries with smaller populations may be able to negotiate lower prices by sourcing from one or two companies rather than relying on multiple manufacturers to provide adequate supply.

Prices will also vary across countries as some use health technology assessments to determine fair purchasing prices. These value assessments-and their role in influencing prices as well as which vaccines are prioritised for procurement-may be shaped by additional evidence regarding their safety and relative efficacy in preventing infection, transmission, or severe outcomes.

Governments and procurement agencies might also consider paying only for vaccines that have received full regulatory approval within a specified time. However, even manufacturers that have set vaccine prices to reflect an ongoing global health emergency ${ }^{4}$ are securing substantial profits from current sales. ${ }^{32}$

Vaccine pricing trends may not function according to normal market forces, paralleling trends of some pharmaceuticals. Analysis of multiple branded medications within the same class found little price competition over time and high correlation between product list prices. ${ }^{33}$ Similar patterns of continued price increases despite multiple manufacturers has also been seen with insulin. ${ }^{34}$ Through monopoly price protections, including intellectual property rights, as well as the lack of transparency around the costs of research and development, manufacturing, and procurement, manufacturers can set and increase prices unless governments and other payers intervene.

Globally, concerns over vaccine pricing have also emerged as countries have secured different prices for the same products through secretly negotiated bilateral agreements. For certain vaccines, some low and middle income countries are paying more than the EU or the US. ${ }^{3-37}$ In response to concerns over vaccine scarcity and pricing, governments and manufacturers have been increasingly called on to waive intellectual property rights, share vaccine technology, and invest in building further manufacturing capacity, particularly in low and middle income countries, to counter the ongoing pandemic and future variants.
South Africa and India have proposed a temporary waiver of intellectual property rights ${ }^{38}$ to prevent any repercussions should countries harness mechanisms such as compulsory licensing, importation, or local production of covid-19 health technologies, including vaccines. The US has also indicated support of a limited waiver for vaccines, ${ }^{39}$ but other high income countries, including those in the EU, remain opposed. $4^{\circ}$

To facilitate technology transfer, the World Health Organization has created a covid-19 technology access pool and covid-19 mRNA vaccine technology transfer hub. 4142 The hub has received around 50 expressions of interest, primarily from countries looking to establish capacity, but none from any current vaccine manufacturers. 43

The Biden administration has also been called on to establish a new licensing agreement for a government owned patent used to produce the vaccine co-developed by the National Institutes of Health and Moderna, which was nearly $100 \%$ funded through public investment. ${ }^{44}$ The agreement would be non-exclusive, allow for local manufacturing of the Moderna vaccine (including in government owned facilities), sharing of vaccine technology with WHO to increase global production, and accessible pricing across countries and payers. Continued public procurements efforts could also ensure reasonable pricing terms are included in purchasing contracts, as the US Department of Defense has done in its agreements with Novavax and Sanofi. 4546

Amid a global pandemic in which vaccines are seen as sources of hope for the end of an ongoing public health crisis, any price for these products may seem reasonable. However, as ongoing efforts to adequately supply and administer covid-19 vaccines worldwide continue, policy makers must pay careful attention to future pricing. Without mechanisms to ensure fair and equitable pricing of covid-19 vaccines beyond the pandemic period, despite the large public investment in their development, countries may face a future of increasing vaccine prices mirroring that of influenza vaccines. The potential absence of an affordable covid-19 vaccine option after the end of the pandemic period is a looming threat to global health that could threaten efforts to ensure long term control of covid-19.

\section{Key messages}

- Uncertainty around future covid-19 vaccine prices has raised concerns about fair and equitable access in the long term

- The influenza vaccine serves as an analogous precedent, in terms of substantial public contribution to its development, need for routine administration, and market with multiple manufacturers

- Public and private sector prices of influenza vaccines have increased in the US over the past 20 years despite a continued increase in numbers of products available and manufacturers

- If the pattern observed with influenza vaccines is repeated, higher prices for covid-19 vaccines will have serious implications for health spending and public health budgets

Contributors and sources: RR is a physician and health services research fellow with a focus on innovation and access to health technologies. She led the writing of this article and is the guarantor. $\mathrm{MD}$ is a medical student who has worked on various health outcomes and regulatory science research projects. She provided analytic support for the article. JSR is a professor in medicine and health policy with expertise in regulatory science research. JLS is a professor in health policy and history of medicine with expertise in vaccination policy and policy making. MD, JSR, and JLS contributed to the conceptualisation and commented on drafts and approved the final version.

Competing interests: We have read and understood BMJ policy on declaration of interests and have the following interests to declare: RR is an employee of the Veterans Health Administration, but the views expressed do not necessarily reflect those of the US Department of Veteran Affairs or the US government. She is a board member for Universities Allied for Essential Medicines North America and the American Medical Student Association Foundation and co-chairs the Doctors for America Drug Affordability Action Team, which is supported by the Laura and John Arnold Foundation. MD and JSR 
receive research support from the FDA for the Yale-Mayo Clinic Center for Excellence in Regulatory Science and Innovation programme. JSR also currently receives research support through Yale University from Johnson and Johnson to develop methods of clinical trial data sharing, and from the Medical Device Innovation Consortium as part of the National Evaluation System for Health Technology, the Agency for Healthcare Research and Quality, the National Heart, Lung and Blood Institute of the National Institutes of Health, and the Laura and John Arnold Foundation. He is an associate research editor at The BMJ. JLS receives research support from the Greenwall Foundation for work related to the topic of this article.

Provenance and peer review: Not commissioned; externally peer reviewed.

1 Cross S, Rho Y, Reddy H, etal. Who funded the research behind the Oxford-AstraZeneca COVID-19 vaccine? Approximating the funding to the University of Oxford for the research and development of the ChAdOx vaccine technology.medRxiv2021 Apr 10. [Preprint.] https://www.medrxiv.org/content/10.1101/2021.04.08.21255103v1

2 BioNTech. BioNTech to Receive up to €375M in Funding from German Federal Ministry of Education and Research to Support COVID-19 Vaccine Program BNT162. 2020. Available from: https://investors.biontech.de/news-releases/news-release-details/biontech-receive-eu375mfunding-german-federal-ministry/

3 US Government Accountability Office. Covid-19: federal efforts accelerate vaccine and therapeutic development, but more transparency needed on emergency use authorizations. 2020. https://www.gao.gov/assets/720/710691.pdf

4 Schakowsky J. Question and answer portion of House oversight and investigations committee hearing: "Pathways to a vaccine: efforts to develop a safe, effective, and accessible covid-19 vaccine" 21 Jul 2020. https://www.youtube.com/watch?V=wVbqNZCtLJY\&feature=youtu.be

5 Cormier Z. The second-generation covid vaccines are coming. Scientific American 2021 Jan 20. https://www.scientificamerican.com/article/the-second-generation-covid-vaccines-are-coming/

6 Tirrell M. Moderna looks to test Covid-19 booster shots a year after initial vaccination. CNBC 2021 Jan 14. https://www.cnbc.com/2021/01/14/moderna-looks-to-test-covid-19-booster-shotsa-year-after-initial-vaccination.html

7 Lovelace B Jr. Pfizer CEO says third Covid vaccine dose likely needed within 12 months. CNBC 2021 Apr 15. https://www.cnbc.com/2021/04/15/pfizer-ceo-says-third-covid-vaccine-dose-likelyneeded-within-12-months.html

8 Moderna. Statement by Moderna on intellectual property matters during the covid-19 pandemic. 2020. https://investors.modernatx.com/news-releases/news-release-details/statement-modernaintellectual-property-matters-during-covid-19/

9 Mancini DP. AstraZeneca vaccine document shows limit of no-profit pledge. Financial Times 2020 Oct 7. https://www.ft.com/content/c474f9e1-8807-4e57-9c79-6f4af145b686

10 Fang L. Drugmakers promise investors they'll soon hike covid-19 vaccine prices. The Intercept 2021 Mar 18. https://theintercept.com/2021/03/18/covid-vaccine-price-pfizer-moderna/

11 Wood P. Pfizer hikes cost of Covid vaccine for EU by 60 per cent. CityAM 2021 Apr 13. https://www.cityam.com/pfizer-hikes-cost-of-covid-vaccine-for-eu-by-60-per-cent/

12 So AD, Woo J. Reserving coronavirus disease 2019 vaccines for global access: cross sectional analysis. BMJ 2020;371:m4750. doi: 10.1136/bmj.m4750 pmid: 33323376

13 Owermohle S. US government buys another 100 million doses of Moderna vaccine. Politico 2020 Dec 11. https://www.politico.com/news/2020/12/11/government-buys-moderna-vaccine444626

14 Pfizer. Pfizer and BioNTech to supply the US. with 100 million additional doses of covid-19 vaccine. Press release, 23 Dec 2020. https://www. pfizer.com/news/press-release/press-releasedetail/pfizer-and-biontech-supply-us-100-million-additional-doses

15 Stevis-Gridneff M, Sanger-Katz M, Weiland N. A European official reveals a secret: the US is paying more for coronavirus vaccines. New York Times 2020 Dec 18. https://www.nytimes.com/2020/12/18/upshot/coronavirus-vaccines-prices-europe-united-states.html

16 World Health Organization. Draft landscape and tracker of COVID-19 candidate vaccines. 2021. https://www.who.int/publications/m/item/draft-landscape-of-covid-19-candidate-vaccines

17 Lavine JS, Bjornstad ON, Antia R. Immunological characteristics govern the transition of COVID-19 to endemicity. Science 2021;371:741-5. doi: 10.1126/science.abe6522 pmid: 33436525

18 National Institutes of Health. NIH clinical trial evaluating Moderna covid-19 variant vaccine begins. Press release, 1 Apr 2021; https://www.nih.gov/news-events/news-releases/nih-clinical-trialevaluating-modera-covid-19-variant-vaccine-begins

19 Pfizer. Pfizer and BioNTech initiate a study as part of broad development plan to evaluate covid-19 booster and new vaccine variants. Press release, 25 Feb 2021. https://www.pfizer.com/news/press-release/press-release-detail/pfizer-and-biontech-initiate-study-part-broaddevelopment

20 Kitchen LW, Vaughn DW. Role of U.S. military research programs in the development of U.S.-licensed vaccines for naturally occurring infectious diseases. Vaccine 2007;25:7017-30. doi: 10.1016/j.vaccine.2007.07.030 pmid: 17728025

21 National Institute of Allergy and Infectious Diseases. Influenza vaccines. https://www.niaid.nih.gov/diseases-conditions/influenza-vaccines

22 FDA. FDA's Critical role in ensuring supply of influenza vaccine. 2020. https://www.fda.gov/consumers/consumer-updates/fdas-critical-role-ensuring-supply-influenza-vaccine

23 Roos R. None of Chiron's flu vaccine is safe, FDA says. CIDRAP 2004 Oct 15. https://www.cidrap.umn.edu/news-perspective/2004/10/none-chirons-flu-vaccine-safe-fda-says
24 Centers for Disease Control and Prevention (CDC). Update: Recommendations of the Advisory Committee on Immunization Practices (ACIP) regarding use of CSL seasonal influenza vaccine (Afluria) in the United States during 2010-11. MMWR Morb Mortal Wkly Rep 2010;59:989-92.pmid: 20703207

25 Schnirring L. Pharmacy chains poised for universal flu vaccination push. CIDRAP News 2010 Aug 18. https://www.cidrap.umn.edu/news-perspective/2010/08/pharmacy-chains-poised-universalflu-vaccination-push

26 Sun LH. CDC and drugmakers boost flu vaccine doses amid fears of an unprecedented respiratory illness season. Washington Post 2020 Jun 24. https://www.washington-

post.com/health/2020/06/24/cdc-drugmakers-boost-flu-vaccine-doses-amid-fears-an-unprecedented-respiratory-illness-season/

27 Centers for Disease Control and Prevention. CDC vaccine price list. 2021 https://www.cdc.gov/vaccines/programs/vfc/awardees/vaccine-management/price-list/index.htm

28 Elder M. The global influenza market. BCC Research, 2018. https://www.bccresearch.com/marketresearch/pharmaceuticals/the-global-influenza-market.html

29 Collis H. UK buys extra 60 million doses of BioNTech/Pfizer covid-19 vaccine. Politico 2021 Apr 28. https://www.politico.eu/article/uk-buys-extra-60-million-doses-of-biontech-pfizer-covid-19vaccine/

30 King R. HHS officials tells Congress COVID-19 booster vaccine shot could be needed. FierceHealthcare 2021 May 11. https://www.fiercehealthcare.com/payer/hhs-officials-tells-congresscovid-19-booster-vaccine-shot-could-be-needed

31 Cernuschi T, Gilchrist S, Hajizada A, Malhame M, Mariat S, Widmyer G. Price transparency is a step towards sustainable access in middle income countries. BMJ2020;368:15375. doi: 10.1136/bmj.15375 pmid: 31932333

32 Robbins R, Goodman PS. Pfizer reaps hundreds of millions in profits from covid vaccine. New York Times 2021 May 4. https://www.nytimes.com/2021/05/04/business/pfizer-covid-vaccineprofits.html

33 Liu P, Dhruva SS, Shah ND, Ross JS. Trends in within-class changes in US average wholesale prices for brand-name medications for common conditions from 2015 to 2020. JAMA Netw Open 2021;4:e2035064. doi: 10.1001/jamanetworkopen.2020.35064 pmid: 33481031

34 Rajkumar SV. The high cost of insulin in the United States: an urgent call to action. Mayo Clin Proc 2020;95:22-8. doi: 10.1016/J.mayocp.2019.11.013 pmid: 31902423

35 Winning A. South Africa to pay $\$ 5.25$ a dose for AstraZeneca vaccine from India’s SII. Reuters 2021 Jan 21. https://www.reuters.com/article/uk-health-coronavirus-safrica-vaccinesidUSKBN290102

36 Raghavan P, Sasi A. Serum Institute's Rs 600/dose for Covishield in private hospitals is its highest rate the world over. Indian Express 2021 Apr 25. https://indianexpress.com/article/india/seruminstitute-covishield-price-india-world-7286635/

37 Nakkazi E. Uganda defends price paid for AstraZeneca Covid19 vaccine; new study suggests vaccine could cut transmission by two-thirds. Health Policy Watch, 2021. https://healthpolicywatch.news/uganda-defends-astrazeneca-price-says-its-not-higher-than-other-countries

38 World Trade Organization. India, South Africa. Waiver from certain provisions of the trips agreement for the prevention, containment and treatment of covid-19.2020. https://docs.wto.org/dol2fe/Pages/SS/directdoc.aspx?filename=q:/P/C/W669.pdf\&Open=True

39 Office of the United States Trade Representative. Statement from Ambassador Katherine Tai on the covid-19 trips waiver. Press release, May 2021. https://ustr.gov/about-us/policy-offices/pressoffice/press-releases/2021/may/statement-ambassador-katherine-tai-covid-19-trips-waiver

40 World Trade Organization. Members approach text-based discussions for an urgent IP response to COVID-19. WTO News 2021. https://www.wto.org/en-

glish/news_e/news21_e/trip_09jun21_e.htm

41 The Peoples Vaccine. FAQ. https://peoplesvaccine.org/faq/

42 World Health Organization. Establishment of a COVID-19 mRNA vaccine technology transfer hub to scale up global manufacturing. 2021. https://www.who.int/news-room/articles-detail/establishment-of-a-covid-19-mrna-vaccine-technology-transfer-hub-to-scale-up-global-manufacturing

43 Lerner S, Fang L. Factory owners around the world stand ready to manufacture covid-19 vaccines Intercept 2021 Apr 29. https://theintercept.com/2021/04/29/covid-vaccine-factory-productionip/

44 Herman B. Moderna skirts disclosures of coronavirus vaccine costs. Axios 2020 Aug 5. https://www.axios.com/moderna-barda-coronavirus-funding-disclosure-2775a517-a775-485aa509-b6906c8535a9.html

45 Ardizzone K. Novavax and Inovio covid-19 vaccine contracts limit prices companies can charge for their products. Knowledge Ecology International 2021 Jan 28https://www.keionline.org/35185

46 Ardizzone K. \$1.8 billion Sanofi vaccine contract contains international reference pricing clause, preserves Standard IP and data rights. Knowledge Ecology International 2020 Dec 2. https://www.keionline.org/34776

This article is made freely available for use in accordance with BMJ's website terms and conditions for the duration of the covid-19 pandemic or until otherwise determined by BMJ. You may use, download and print the article for any lawful, non-commercial purpose (including text and data mining) provided that all copyright notices and trade marks are retained. 